\title{
Cobalt (II)-EDTA complex as a new reductant for phosphomolybdic acid used for the assay of trazodone
}

\author{
A V S S PRASAD and C S P SASTRY* \\ Foods and Drugs Laboratories, School of Chemistry, Andhra University, \\ Visakhapatnam 530 003, India \\ e-mail: avssprasad@rediffmail.com
}

MS received 1 June 2002; revised 7 October 2002

\begin{abstract}
A new spectrophotometric method for the assay of trazodone (TZ) has been described. TZ forms a complex in stoichiometric proportions with phosphomolybdic acid. The released phosphomolybdic acid from the complex with acetone is reduced with a new reductant (cobalt nitrate-ethylenediamine tetra acetic acid) to molybdenum blue, which has maximum absorption at $840 \mathrm{~nm}$. Beer's law limits, precision and accuracy of the methods are checked by the UV reference method. This method is found to be suitable for the assay of $\mathrm{TZ}$ in the presence of other ingredients that are usually present in tablets. Recoveries are almost quantitative.
\end{abstract}

Keywords. Trazodone; phosphomolybdic acid; cobalt nitrate; ethylenediamine tetra acetic acid.

\section{Introduction}

Trazodone (as hydrochloride) ${ }^{1}$ is an antidepressant, which is chemically known as 1, 2, 4trizolo [4, 3-a] pyridin-3 (2H)-one, 2-[3-[4-(3-chlorophenyl)-1-piperazinyl]propyl]-, monohydrochloride. Literature survey reveals that only extraction spectrophotometric methods $^{2}$ were reported for the assay of TZ. Phosphomolybdic acid (PMA, $\mathrm{H}_{3} \mathrm{PO}_{4} \cdot 12 \mathrm{MoO}_{3} \cdot 2 \mathrm{H}_{2} \mathrm{O}$ ) is widely employed as a reagent in the quantitative analysis of several drugs. It forms insoluble adduct (yellowish precipitates) with various groups of drugs and released PMA from the adduct is usually measured by colourimetry due to blue-green colour formation by the reduction of PMA. The reduction of PMA by various reductants like ascorbic $\mathrm{acid}^{3}$ or hydrazine hydrate ${ }^{4}$ to yield molybdenum blue is well known. Surprisingly, the reduction of PMA by cobalt nitrate-ethylenediamine tetra acetic acid (Co(II)-EDTA) complex has not been exploited. The efforts in this resulted in (CO(II)-EDTA) complex being used as a new reductant for PMA in the assay of TZ.

\section{Experimental}

Aliquots of standard TZ solution $(0.5-2.5 \mathrm{ml}, 200 \mu \mathrm{g} / \mathrm{ml}$ in $0.01 \mathrm{M} \mathrm{HCl})$ were delivered into a series of centrifuge tubes and the volume in each tube was adjusted to $3.0 \mathrm{ml}$ with $0.01 \mathrm{~N} \mathrm{HCl}$. Then $1.5 \mathrm{ml}$ of phosphomolybdic acid $\left(5.47 \times 10^{-3} \mathrm{M}\right)$ was added and centrifuged for $5 \mathrm{~min}$. The precipitate was collected through filtration followed by

*For correspondence 
washing with distilled water until it is free from the reagent. The precipitate in each tube was dissolved in $5 \mathrm{ml}$ of acetone and transferred into a $25 \mathrm{ml}$ graduated test tube. One $\mathrm{ml}$ each of cobalt nitrate $\left(1.03 \times 10^{-1} \mathrm{M}\right)$ and EDTA $\left(1.07 \times 10^{-1} \mathrm{M}\right)$ solutions were successively added and the tubes were heated for $10 \mathrm{~min}$ at $60^{\circ} \mathrm{C}$. The test tubes were cooled and the solution in each tube was made upto the mark with distilled water. The absorbance was measured at $840 \mathrm{~nm}$ against a similar reagent blank. The amount of TZ was calculated from Beer's law plot.

\section{Results and discussion}

\subsection{Fixation of optimum conditions}

The optimum conditions for the development of colour were established by varying the parameters one at a time, keeping the others fixed and observing the effect produced on the absorbance of the coloured species. The following experiments were conducted for this purpose and the conditions so obtained were incorporated in recommended procedures. For the quantitative precipitation of TZ 1.2 to $1.8 \mathrm{ml}$ of $5.47 \times 10^{-3} \mathrm{M}$ phosphomolybdic acid was found to be sufficient to cover the broad range of Beer's law limits. Addition of excess PMA content does not produce any excess of the precipitate. Distilled water was suitable for washing the precipitate. The precipitate was dissolved when it was washed with alcohol. Acetone was able to dissolve the precipitate and release phosphomolybdic acid. In the preliminary investigations, reducing agents such as hydrazine hydrate $\left(\lambda_{\max }, 715 \mathrm{~nm} ; \varepsilon_{\max }, 5.21 \times 10^{2} 1 \mathrm{~mol}^{-1} \mathrm{~cm}^{-1}\right)$, ascorbic acid $\left(\lambda_{\max }\right.$, $\left.715 \mathrm{~nm} ; \varepsilon_{\max }, 1.22 \times 10^{3} 1 \mathrm{~mol}^{-1} \mathrm{~cm}^{-1}\right)$ and Co(II)-EDTA complex $\left(\lambda_{\max }, 840 \mathrm{~nm} ; \varepsilon_{\max }\right.$, $1.00 \times 10^{4} 1 \mathrm{~mol}^{-1} \mathrm{~cm}^{-1}$ ) were used to reduce the released phosphomolybdic acid. Since the $\mathrm{Co}$ (II)-EDTA complex produces high $\lambda_{\max }$ and $\varepsilon_{\max }$ values, it was preferred for the reduction of phosphomolybdic acid. Maximum absorbance was obtained at a volume range of 0.8 to $1.2 \mathrm{ml}$ each of $1.03 \times 10^{-1} \mathrm{M} \mathrm{Co}(\mathrm{II})$ and $1.07 \times 10^{-1} \mathrm{M}$ EDTA. Absorbance decreases if the volume of $\mathrm{Co}$ (II) is increased further. However, there is no impact on the absorbance if the volume of EDTA is increased further. The order of addition of reagents (i.e. EDTA plus $\mathrm{Co}(\mathrm{II})$ ) has no significant effect. So list volumes of PMA $\left(1.5 \mathrm{ml}, 5.47 \times 10^{-3} \mathrm{M}\right), \mathrm{Co}(\mathrm{II})\left(1.0 \mathrm{ml}, 1.03 \times 10^{-1} \mathrm{M}\right)$ and EDTA $(1.0 \mathrm{ml}$, $\left.1.07 \times 10^{-1} \mathrm{M}\right)$ were preferred for further investigations. The maximum intensity $\left(\lambda_{\max }\right.$, $750 \mathrm{~nm} ; \varepsilon_{\max }, 5.39 \times 10^{3} 1 \mathrm{~mol}^{-1} \mathrm{~cm}^{-1}$ ) was obtained after one hour if the reaction mixture was kept at room temperature. However, on heating to $60^{\circ} \mathrm{C}$ in a hot water bath, maximum intensity of colour was attained within $7 \mathrm{~min}$ and bathochromic shift and hyperchromic effect were observed $\left(\lambda_{\max }, 840 \mathrm{~nm} ; \varepsilon_{\max }, 1.00 \times 10^{4} 1 \mathrm{~mol}^{-1} \mathrm{~cm}^{-1}\right)$. The colour product was stable for up to $2 \mathrm{~h}$.

\subsection{Interference studies}

The effect of various substances that often accompanied with $\mathrm{TZ}$ in various pharmaceutical formulations was studied. To an aliquot containing $300 \mu \mathrm{g}$ of $\mathrm{TZ}$, different amounts of various ingredients and additives were added individually until a solution showed the same abosrbance $( \pm 0.01)$ as that of pure $\mathrm{TZ}$ solution under experimental conditions as described under the procedure. The commonly used concomitants and additives in the preparation of formulation such as talc (up to 200-fold (excess) $(w / v)$, starch (150-fold), boric acid (150-fold), stearic acid (70-fold), magnesium stearate (50- 
fold), kaolin (30-fold), sodium lauryl sulphate (10-fold) and gelatin (10-fold) did not interfere with the assay of TZ by proposed method.

\subsection{Analytical data}

The optical characteristics such as Beer's law limits, molar absorptivity and Sandell's sensitivities were found to be $4-20 \mu \mathrm{g} / \mathrm{ml}, 1.00 \times 10^{4} 1 \mathrm{~mol}^{-1} \mathrm{~cm}^{-1}$ and $0.040 \mu \mathrm{g} \mathrm{cm}^{-2}$ (0.01 absorbance unit) respectively. Slope, intercept and correlation coefficient data from linear least square treatment for TS were found to be $2.46 \times 10^{-2},-1.00 \times 10^{-4}$ and 0.9999 respectively. The percent relative standard deviation and percent range of error $(95 \%$ confidence limits) from six replicate samples have been found to be 0.477 and 0.0494 respectively. Pharmaceutical formulations containing TZ $(0.5-2.5 \mathrm{ml}, 200 \mu \mathrm{g} / \mathrm{ml}$ in $0.01 \mathrm{M} \mathrm{HCl}$ ) were successfully analysed by proposed method and the results obtained were compared with UV reference method. ${ }^{1}$ This comparison shows that there is no significant difference between the results of studies methods and those of the reference one, while the similarity of the results is an obvious evidence that during the application of this method, the additives and excipients that are usually present in pharmaceutical formulations do not interfere with the assay by proposed methods. The recoveries range from $99 \cdot 16$ to $100 \%$.

\section{Chemistry of the coloured species}

The present method involves two steps. First step is the quantitative precipitation of TZ with PMA. Second step is the reduction of PMA (released with acetone from its adduct)

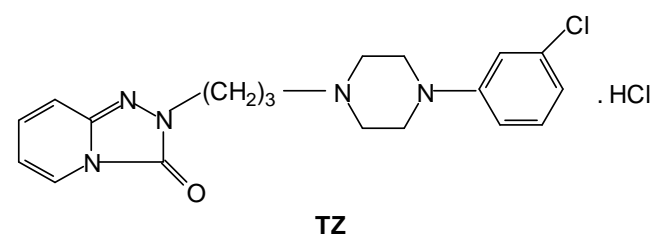

Step-1:

$$
\mathrm{TZ}+\mathrm{PMA} \rightarrow \underset{(\mathrm{ppt})}{\mathrm{TZ}-\mathrm{PMA}} \quad+\underset{\text { (unreacted) }}{\mathrm{PMA}}
$$

Step-2:

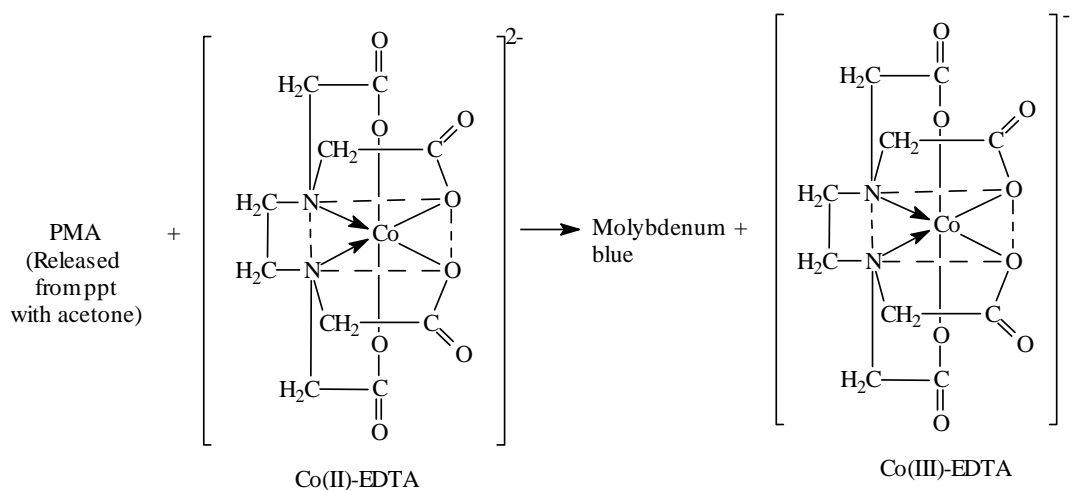

Scheme 1. 
by $\mathrm{Co}(\mathrm{II})$-EDTA complex to yield molybdenum blue. Molybdenum blue ${ }^{5}$ is the result of a mild reduction of a neutral solution, which contains $\mathrm{Mo}(\mathrm{VI})$ either as an iso or a hetero poly molybdate anion or as a suspension of $\mathrm{MoO}_{3}$ in water. The molybdenum blue contains both oxide and hydroxide with an $\mathrm{MoO}(\mathrm{OH})_{2}$, an olive green compound as one limit and $\mathrm{MoO}_{3}$ as the other. The compounds in which the mean oxidation state of Mo is between $5+$ and $6+$ are the blue ones [e.g. $\mathrm{MoO}_{2}(\mathrm{OH})$ and $\mathrm{MoO}_{2.5}(\mathrm{OH})_{0.5}$ ]. The tone of the colour of a reduced solution of $\mathrm{Mo}(\mathrm{VI})$ changes between the emarald-blue and the deep ultra marine-blue, as a function of the concentration of each absorbant particle, which results from the reduction of the Mo(VI). Obviously, the variation of the colour causes the simultaneous change of the $\lambda_{\max }$ (from $750 \mathrm{~nm}$ to $840 \mathrm{~nm}$ ) and $\varepsilon_{\max }$ of the treated solution. It appears that this change between the values of $\lambda_{\max }$ owing to the qualitative and quantitative of the absorbent particles which is consequence of the different conditions (variation in the temperature) for the reduction of $\mathrm{Mo}(\mathrm{VI})$. The probable sequence of reactions proposed for this method are given in scheme 1 .

\section{Conclusions}

The newly proposed spectrophotometric method for the assay of $\mathrm{TZ}$ is simple, sensitive, selective and reliable. The colour reaction does not require stringent conditions nor many reagents or solvents. The advantage of this method is that there is no extraction procedure nor interference of ingredients or additives as that of the reported methods. The statistical data is in good agreement with the reference method. Hence, this method can be suitable for the micro-determination of $\mathrm{TZ}$ in pure and pharmaceutical formulations in quality control laboratories depending upon the needs of situation and availability of facilities.

\section{References}

1. United States Pharmacopoeia 2000 24th edn, USP Convention, Inc., Rockville, p. 1682

2. Ayad M M, Khalil H M and El-Hanawea M H M 1999 Sci. Pharm. 67241

3. Sanghavi N M and Pai M G 1974 Indian J. Pharm. 71

4. Sanghavi N M and Chandramohan H S 1976 Indian J. Pharm. 42

5. Issopoulos P B 1989 Pharm. Acta Helv. 9280 